\title{
Jornalismo impresso na era digital: uma crítica à segmentação do público e à fragmentação do noticiário
}

Gabriela Nóra ${ }^{1}$

\begin{abstract}
Resumo: A análise da mídia impressa evidencia que a especialização temática, seguida da fragmentação do noticiário, é uma tendência mundial que tem se acentuado com o avanço das Tecnologias de Informação e Comunicação. O trabalho busca refletir sobre os processos de segmentação do público e de fragmentação do noticiário, no contexto da temporalidade imediata e da desvalorização da memória frente a um presente contínuo e efêmero. Um cenário no qual "textos curtos e em carreira suicida" tentam competir com a TV e a web, em lugar de construírem os grandes gêneros que não se encontram em nenhuma delas.
\end{abstract}

Palavras-chave: jornalismo impresso, segmentação, novas tecnologias, temporalidade.

Abstract: The printed media analysis shows that theme specialization, followed by news fragmentation, is a general tendency reinforced by the improvement of Communication and Information Technologies. The paper aims to reflect about the public segmentation and news fragmentation process, considering immediate temporality context and memory devaluation faced a continuous and ephemeral present. A scenario in which "shorts texts in suicidal route" try to compete with the web and the TV instead of delivering great genres that are not available in none of them.

Keywords: print journalism, segmentation, news technologies, temporality. 
"Poucas mudanças são tão desconcertantes como as que afetam a nossa percepção coletiva do tempo."

(MARTÍN-BARBERO, 2006, p.70)

Nos últimos anos, pesquisas sobre o futuro dos jornais impressos têm adquirido importância diante da tão anunciada crise do setor. Não só as modernas tecnologias digitais e a internet ameaçam os periódicos tradicionais, mas também o crescimento dos mercados de jornais populares e dos de distribuição gratuita, o fortalecimento da mídia comunitária e o desenvolvimento de novas formas de se buscar e trocar informações. Todo esse cenário, sob o rótulo de que se vive hoje na Sociedade da Informação, indica que é tempo de mudanças. Mudanças que impõem reflexões sobre os modernos processos comunicacionais, mas que demandam igualmente, e de forma urgente, novos olhares sobre antigas estruturas.

Como conciliar o esforço de padronização, característico dos tradicionais meios de comunicação de massa, com a diversidade de públicos cada vez mais fragmentários e a fabricação de nichos de consumo mais e mais especializados? Com o aumento da especialização, é possível ao jornal impresso manter a sua unidade e, ao mesmo tempo, atender a interesses tão diversos? A resposta veio com a "cadernização" e as sucessivas fragmentações do noticiário, sem, contudo, que se atentasse para os prejuízos à sua unidade.

Tendo os jornais percebido a existência de públicos diferenciados não há uma audiência única, homogênea - fragmentaram-se em cadernos visando atender aos mais diferentes grupos e, principalmente, facilitar o trabalho da publicidade. Tal estratégia resultou nas crescentes segmentações de assuntos e do público-leitor, favorecendo sobremaneira as investidas do marketing, apesar dos danos sociais causados pela descontextualização de fatos e informações, pela ausência de relações entre as diversas áreas temáticas, pela falta de entrosamento entre as diferentes editorias. Enfim, por uma série de fatores que têm como base a fragmentação do pensar, do fazer e do conceber a atividade jornalística. 
Não há dúvidas de que nesse percurso os jornais vêm perdendo a sua unidade. Além disso, em tempos de mídia digital, assiste-se a um acelerado processo de "atomização" do indivíduo. A nova mídia vem se expandindo em larga escala e atinge cada vez mais pessoas. No entanto, se na televisão e no rádio a comunicação se dá simultaneamente para um público massivo e, no jornal impresso, um mesmo noticiário é lido por várias pessoas, mas em diferentes momentos, não necessariamente simultâneos - cada qual pode ler o jornal quando Ihe for mais conveniente durante o dia, ou mesmo em dias diferentes -, com a mídia digital caminha-se para uma comunicação cada vez mais especializada e pronta para as demandas mais pessoais, sejam elas referentes ao momento de leitura ou visualização/audição de um conteúdo (texto, imagem, áudio, vídeo etc.) ou mesmo referentes ao próprio conteúdo que será acessado.

Ou seja, a comunicação digital, através dos mais avançados meios existentes (computadores, laptops, celulares e demais portáteis) e dos que ainda virão com o acelerado desenvolvimento tecnológico, caminha para um aperfeiçoamento da especialização, servindo a cada indivíduo conforme as suas necessidades. Ampliam-se as possibilidades de escolha e cada qual pode buscar aquilo que mais Ihe atende em termos de informação, entretenimento, serviços etc. Ainda que os grandes conglomerados tenham migrado para a internet, com todo o seu know-how e credibilidade, pode-se falar em novos atores, novos produtores de conteúdo e fontes de informação. Uma nova realidade que põe em xeque, como nunca antes na história, a hegemonia dos tradicionais veículos de comunicação de massa.

Não se quer dizer com isso que tais veículos estejam de todo ameaçados, mas apenas que o novo cenário demanda uma urgente reestruturação da mídia tradicional. No que tange aos jornais impressos, torna-se indispensável não só repensar os conteúdos por eles veiculados, mas também a sua forma de organização, isto é, a estrutura que determina os modos de apresentação desses conteúdos. 
Nesse ínterim, acredita-se que a análise de como os fatos sociais são representados pelos jornais implica uma revisão das lógicas de classificação e segmentação do noticiário. O modelo atual dos jornais impressos, com a apresentação fragmentada do noticiário e a excessiva segmentação do público, impossibilita uma efetiva contextualização dos acontecimentos e o pleno cumprimento da função social do jornalismo, qual seja a de informar e não apenas a de noticiar fatos isolados.

Em tempos de comunicação digital, mais do que nunca os jornais precisam buscar novos formatos, já que não podem competir, em termos de quantidade de informação, sedução visual e capacidade de interação, com as modernas Tecnologias de Informação e Comunicação.

\begin{abstract}
Estamos no umbral de um mundo de notícias caótico e fraturado, caracterizado por mais diálogo e menos jornalismo de primeira qualidade. A transformação dos jornais - de empresas dedicadas à reportagem objetiva em feixes de comunidades engajadas com suas próprias 'notícias' - significará a perda de uma narrativa nacional em torno de 'fatos' consensuais (Caderno Mais! Folha de S. Paulo, 8 de junho de 2008, p. 8).
\end{abstract}

Eric Alterman, jornalista norte-americano e professor da Universidade da Cidade de Nova York, cita o cientista político Benedict Anderson, que, no livro "Comunidades Imaginadas" (1983), recorda a comparação hegeliana do ritual de leitura do jornal à prece matutina: "Cada qual sabe que a mesma cerimônia é repetida simultaneamente por milhares ou milhões de outros, em cuja existência confiamos, mas sobre cuja identidade não fazemos a menor idéia" (Caderno Mais! Folha de S. Paulo, 8 de junho de 2008, p. 8), chamando a atenção para o fato de que os jornais cumprem um importante papel na criação de um terreno comum a todos os seus leitores e de uma imagem de mundo que todos habitam.

Entretanto, no afã de acompanharem a velocidade e a quantidade de material informativo disponibilizado pela mídia digital, os jornais têm adotado uma estratégia que vai de encontro a duas de suas funções mais primordiais: colocar o foco sobre o interesse público e fazer uma reflexão cotidiana sobre a 
realidade. Esse seria o seu papel e o seu futuro, segundo observa Eleonora de Lucena, editora executiva do jornal Folha de S. Paulo, em artigo sobre o futuro dos impressos. Lucena lembra ainda que, marcando a ascensão da burguesia, a imprensa teve papel decisivo ao elevar as massas a protagonistas da história. Além disso e, especialmente hoje,

os jornais condensam uma credibilidade difícil de ser replicada em outros meios e funcionam como uma bússola para o leitor imerso no caos informativo atual. Apresentam um resumo organizado das notícias mais importantes das últimas 24 horas, selecionando e hierarquizando fatos, análises e opiniões (Caderno Mais! Folha de S. Paulo, 8 de junho de 2008, p. 4).

Por esta razão, e diante da impossibilidade de os jornais impressos competirem ou mesmo aproximarem-se das novas mídias, em termos de velocidade, apelo visual e sensitivo e quantidade de informação disponibilizada ao leitor - os recursos gráficos dos impressos, por mais evoluídos que sejam, tampouco podem disputar atenção com as diversas formas de apresentação de conteúdos na rede, englobando simultaneamente, textos, fotos, vídeos, sons, efeitos, animações etc. -, há um certo consenso entre os especialistas que acreditam na sua coexistência com a mídia digital. Eles afirmam que esta só será possível se os impressos se voltarem para a qualidade de suas publicações, buscando maior profundidade e contextualização das notícias.

Não há dúvidas de que a cultura de imprensa impõe um padrão homogeneizante. Pois, a modernidade sim tem diversidade, fragmentação, mas também a padronização é fundamental para atingir a todos, para combater a volatilidade, até mesmo para que as pessoas tenham um vocabulário de troca. No entanto,

o longo curso que deixa para trás a mídia de massa e vai em direção à segmentação parece continuar. Essa tendência afeta mais do que nossa mídia tradicional. Ela envolve nossa capacidade de manter uma política cultural unificada com valores compartilhados. A internet não criou esse problema, mas o está acelerando (MEYER, 2007, p. 257). 
Como observa o pesquisador norte-americano Philip Meyer, a internet é apenas o mais recente de tantos outros avanços que contribuíram para a segmentação dos mass media. Mas, pelo fato de atender de forma cada vez mais eficiente àqueles que buscam informação segmentada, a internet tem acelerado essa tendência rumo a públicos menores. Seguindo essa lógica, a grande imprensa, ao constatar a existência de diferentes segmentos sociais com demandas específicas, (re)fragmenta o seu noticiário, oferecendo ao público blocos de informações cada vez mais restritas.

\title{
A grande fábrica de um 'presente autista'
}

\begin{abstract}
O descentramento não o é só da sociedade, mas também dos indivíduos, que agora vivem uma integração parcial e precária das múltiplas dimensões que os conformam. O indivíduo já não é o indivisível, e qualquer unidade que se postule tem muito de "unidade imaginada". Mas isso não pode ser confundido com a celebração da diferença transformada em fragmentação, proclamada por boa parte do discurso pós-moderno e rentabilizada pelo mercado. A celebração das identidades débeis (fragmentadas) tem uma forte relação com outra celebração, a da desregulação do mercado, exigida pela ideologia neoliberal (MARTÍNBARBERO, 2006, p.60).
\end{abstract}

Jesús Martín-Barbero lembra que é preciso pensar a "hegemonia comunicacional do mercado", isto é, a conversão da comunicação em instrumento de inserção da cultura no espaço/tempo do mercado e das tecnologias, num momento em que a comunicação se encontra fortemente atrelada a uma "razão comunicacional cujos dispositivos - a fragmentação que desloca e descentra, o fluxo que comprime e globaliza, a conexão que desmaterializa e hibridiza agenciam o devir do mercado da sociedade". (MARTÍN-BARBERO, 2006: 53). Além disso, o teórico colombiano diz preocupar-se com o que chama de "perda do mínimo horizonte cultural comum" e alerta para que não mais se confunda diversidade sócio-cultural com fragmentação. 
No que diz respeito ao jornalismo impresso, é fácil perceber como a segmentação do público e a fragmentação do noticiário estão intimamente relacionadas ao 'devir do mercado', com sérios prejuízos à integração social e à manutenção do 'mínimo horizonte cultural comum' de que fala Barbero. Neste sentido, vale recorrer à tese de doutorado em Comunicação e Semiótica, do professor Rafael Souza Silva, da Universidade Católica de Santos, que trata do processo de "cadernização" do jornalismo impresso diário.

O professor explica que o termo "segmentação" - equivalente à divisão, setor, parte de um todo, entre outras significações -, no jornalismo impresso, é utilizado para definir "a qualidade básica de informação e justaposição de conteúdos de uma publicação que tem por objetivo principal atender às necessidades de uma fatia específica do mercado" (SOUZA SILVA, 1996: 22). Sua tese tem por objetivo demonstrar como o processo de "cadernização" do jornalismo impresso assemelha-se ao chamado efeito zapping ${ }^{2}$ da mídia eletrônica. O autor argumenta que a segmentação em cadernos estimula a leitura como um jogo, no qual estariam implícitos o culto à tecnologia e ao ritmo acelerado das modernas sociedades de consumo.

Do mesmo modo que o telespectador ou o radiouvinte munido de um controle remoto rastreia em segundos a programação das emissoras de rádio e televisão, o leitor de jornais, numa relação análoga, seleciona o caderno de leitura com assuntos específicos, desprezando vários outros que, certamente, terão públicos distintos (SOUZA SILVA, 1996, p.12).

Para Souza Silva, a "cadernização" não é apenas resultado das estratégias mercadológicas que impulsionaram modificações na estrutura dos periódicos nas últimas décadas. A fragmentação e a aceleração da atividade de leitura, provocadas pela excessiva divisão dos jornais, seriam também frutos do desenvolvimento tecnológico e de seu poder transformador:

O zapping jornalístico é uma abstração. Produto da cultura tecnologizada das modernas sociedades de consumo. O culto tecnológico e o mito da velocidade são os novos símbolos modeladores de um novo tempo, 
caracterizado pela aceleração. Criam-se novos códigos e, com eles, novos valores culturais (SOUZA SILVA, 1996, p.16).

Da mesma forma, Barbero ressalta que as tecnologias não são ferramentas transparentes: "elas não se deixam usar de qualquer modo: são em última análise a materialização da racionalidade de uma certa cultura e de um 'modelo global de organização do poder"' (MARTÍN-BARBERO, 2003, p.268). Assim, de acordo com ele, cada vez mais a tecnologia é menos ferramenta e mais mediação de transformação profunda do mundo.

A técnica não é um conjunto de aparatos, mas um sistema misto de aparatos e de saberes que se materializam em aparatos, explica o pesquisador colombiano. Logo, nem técnica (instrumento), nem tecnologia (dimensão ideológica), uma vez que, ainda segundo Barbero, a profunda mudança da técnica hoje merece que se pronuncie tecnicidade - termo que marca a passagem da técnica máquina à técnica cérebro, da técnica instrumental à tecnicidade estrutural, sendo esta última referente ao caráter estruturador que a tecnologia tem na sociedade. Trata-se, pois, tal como afirma Manuel Castells, da integração crescente entre mentes e máquinas,

inclusive a máquina de DNA, [que] está anulando o que Bruce Mazlish chama de a "quarta descontinuidade" (aquela entre seres humanos e máquinas), alterando fundamentalmente o modo pelo qual nascemos, vivemos, aprendemos, trabalhamos, produzimos, consumimos, sonhamos, lutamos ou morremos (CASTELLS, 1999, p.51).

Novos modos de percepção e de linguagem, novas sensibilidades e escrituras, novos modos de relação entre os processos simbólicos e as formas de produção e distribuição dos bens e serviços. É o que afirma Barbero, ressaltando que se está diante de uma mediação tecnológica que não é meramente instrumental, mas estrutural.

Com o computador estamos não em frente a uma máquina com a qual se produzem objetos, mas, sim, diante de um novo tipo de tecnicidade, 
que possibilita o processamento de informações e cuja matéria-prima são abstrações e símbolos. O que inaugura uma nova fusão de cérebro e informação que substitui a tradicional relação do corpo com a máquina (MARTÍN-BARBERO, 2006, p.57).

A atual dinâmica da sociedade, movida pelo desejo de consumo desenfreado e pela aceleração dos processos de troca de mercadorias e informações, impõe uma rápida e completa apropriação do tempo. Como argumenta o professor Dênis de Moraes, da Universidade Federal Fluminense, vive-se "a tirania do fugaz" e a sociedade aparenta não mais sobreviver sem as tecnologias que atualizam a existência ininterruptamente. Moraes cita o escritor britânico John Berger (2004) para destacar a efemeridade do tempo, das relações e das trocas, num momento em que "tudo dilui-se e restabelecese sem direito a intervalos":

É um espaço sem horizonte. Tampouco há continuidade entre as ações, nem pausas, nem atalhos, nem linhas, nem passado nem futuro. Vemos apenas o clamor de um presente desigual e fragmentário. Está cheio de surpresas e sensações, mas não aparecem em lado algum suas conseqüências ou seus resultados. Nada flui livremente; há apenas interrupções (BERGER apud MORAES, 2006, p.33).

No culto ao fugaz, explica o professor, "querem convencer-nos de que o que perdemos em durabilidade ganhamos em intensidade" (MORAES, 2006: 36). Impera, pois, a lógica da "velocidade como virtude", da "velocidade como emblema atávico de evolução sociotécnica" (MORAES, 2006: 46). Ou seja, nada pode escapar e tudo deve ser apreendido o mais depressa possível. Daí a necessidade de fragmentar o real, de subdividi-lo tantas vezes quantas forem necessárias para facilitar o fluxo contínuo e veloz de dados e mensagens.

A ruptura da narração e a preeminência do fluxo de imagens que aí se produzem encontram sua expressão mais certeira no zapping com o qual o telespectador, ao mesmo tempo que multiplica a fragmentação da narração, constrói com seus pedaços um outro relato, um duplo, puramente subjetivo, intransferível, uma experiência incomunicável. Estaríamos aproximando-nos do final do percurso que W. Benjamin vislumbrou ao ler no declive da 
narração a progressiva incapacidade dos homens para compartilhar experiências (MARTÍN-BARBERO, 2006, p.73).

Bem se sabe que, no conhecido texto de Walter Benjamin sobre a morte do narrador, é atribuído à difusão da informação, com o surgimento da imprensa, um papel decisivo no declínio da arte de narrar. Vale, entretanto, mais uma vez, destacar o trecho no qual o autor chama a atenção para o fato de que a morte do narrador carrega em si um grave sintoma: a dificuldade de se partilharem experiências:

a arte de narrar está em vias de extinção. São cada vez mais raras as pessoas que sabem narrar devidamente. Quando se pede num grupo que alguém narre alguma coisa, o embaraço se generaliza. É como se estivéssemos privados de uma faculdade que nos parecia segura e inalienável: a faculdade de intercambiar experiências (BENJAMIN, 1987, p.198).

Acrescenta-se a essa privação, no caso do jornalismo impresso, a incapacidade de se cruzarem dados e informações. O noticiário apresenta-se de modo fragmentário, como se as notícias fossem auto-explicativas, autoafirmativas. No entanto, toda informação é necessariamente relacional. Mas a pretensão objetiva de agarrar o enunciado acarreta o esquecimento do aspecto relacional, ficando-se apenas com o aspecto dado. É o que afirma o professor Muniz Sodré, alertando para o fato de que, com a internet, cada vez mais a relação é deixada de lado, em favor das notícias curtas e rápidas.

Sodré cita o jornalista norte-americano Robert Ezra Park, da Escola de Chicago, que assinalava dois tipos de conhecimento na notícia: o acquaintance with ("familiaridade com") e knowledge about ("saber sobre"), distinguindo-os pelo grau de profundidade. O primeiro, não-sistemático e fragmentário, partiIhado em maior extensão; o segundo, mais sistemático ou analítico.

Com o advento da mídia eletrônica e, principalmente, da mídia digital, percebe-se uma diminuição da sistematização discursiva da informação. Para Sodré, tal fato remete à importância da densificação do acontecimento, de se 
completar a informação com um conhecimento mais sistemático; aquele que é capaz de surpreender cognitivamente o leitor, transcendendo a pura e simples factualidade. Isto porque, segundo ele, mesmo a notícia pode (e deve) ser ampliada em termos reflexivos, indo de encontro a um jornalismo que progride tão somente por refinamento de suas técnicas, em um ambiente - a internet - caracterizado pela sede de informação e, conseqüentemente, pelo vício no conhecimento fragmentário.

Assim, segundo Sodré, pouco interessa o conteúdo do que é noticiado, pois, o que está em questão é o acesso rápido. Logo, a notícia seria, desse ponto de vista, uma forma incipiente da economia da atenção, corroborando com a idéia de notícia como um produto; produto caro e altamente perecível, que deve ser consumido o quanto antes e em menor tempo possível. O que ajuda a explicar o modo de elaboração do noticiário a partir do enquadramento e da hierarquização dos fatos marcados, em função de públicos específicos.

[...] nada transparece no produto informativo acabado: as diversas restrições que pouco a pouco influenciam a escolha das notícias são canceladas por uma apresentação que intencionalmente se dá como "simples" relatório do que ocorreu no mundo nas últimas 24 horas (ALTHEIDE-RASMUSSEN apud WOLF, 2005, p.257).

A produção cotidiana de informações, ou seja, a conversão de acontecimentos em notícias, pode ser dividida, segundo o sociólogo italiano Mauro Wolf, em três fases principais: 1) coleta: à fase de coleta segue, quase simultaneamente, a de estruturação do material, uma vez que a primeira ocorre sobretudo por meio de fontes estáveis (como as agências), que produzem material informativo que pode ser facilmente inserido nos procedimentos de produção da redação, atendendo à necessidade de fluxo constante e seguro de notícias; 2) seleção: processo complexo que se desenvolve ao longo de todo o ciclo de produção da notícia, tendo em vista a distribuição de três recursos escassos: equipe, formato e tempo de produção; 3) apresentação: tem por 
objetivo anular os efeitos provocados pela organização da produção, a fim de 'restituir' à informação o seu aspecto de espelho da realidade.

A fragmentação dos conteúdos e da imagem da realidade social colocase precisamente entre estes dois movimentos: de um lado, a extração dos acontecimentos do seu contexto, de outro, a reinserção dos eventos noticiáveis no contexto constituído pela "confecção", pelo formato do produto informativo. [...]: o mecanismo de acréscimo de sentido, ligado à aproximação de duas notícias entre si, aos critérios de calibragem do ritmo interno do noticiário, às inferências que podem ser feitas a partir da ordem em que são dispostas as próprias notícias, encontra-se dentro das delimitações do formato em ação (WOLF, 2005, p.259).

Formato este, embora aberto a eventuais mudanças, caracterizado por sua rigidez, cuja principal função é atender à racionalização das rotinas produtivas. Logo, é preciso atentar para o fato de que o processo de fragmentação dos conteúdos e a distorção da realidade são inerentes à própria técnica de estruturação da notícia. Este pensamento é compartilhado por diversos autores que trabalham com a hipótese da fragmentação da notícia como uma técnica mercadológica e consideram que, como qualquer outro produto, a notícia está sujeita aos processos de mercantilização do capitalismo.

Segundo Wolf, pesquisas sobre o conteúdo dos telejornais (mas não apenas destes) apontam para uma fragmentação da imagem da sociedade, mediante a justaposição de acontecimentos-notícia, apresentados como auto-suficientes. Ou seja, o que se verifica, na maioria dos casos, é um noticiário de nível superficial e fora de contexto. Em geral, as matérias valorizam o lead - "o centro das atenções está no que ocorre, não na razão pela qual ocorre ou em suas causas profundas" (EPSTEIN apud WOLF, 2005: 199) -, em prejuízo das informações de background, dificultando o aprofundamento e a compreensão de aspectos subjacentes, porém significativos, aos fatos apresentados como notícias.

O que, em geral, é transmitido ao público é a localização dos acontecimentos, os indivíduos envolvidos com eles, e detalhes como os nomes geográficos, das personagens públicas, de indústrias 
etc. Com freqüência, esses elementos ocupam automaticamente o primeiro lugar na memória dos destinatários, enquanto as causas e as conseqüências dos eventos permanecem em segundo plano. 0 resultado global é uma lembrança fragmentária, em que os indivíduos conservam detalhes isolados, mas não o contexto (FINDHAL-HÖIJER apud WOLF, 2005, p.1999).

Portanto, pode-se afirmar, ainda com Wolf, que os fatores que determinam a noticiabilidade (sejam eles relativos à cultura profissional ou à organização das práticas produtivas) permitem que se realize cotidianamente a cobertura informativa, no entanto, constituem elementos da distorção involuntária, na medida em que dificultam o aprofundamento e a compreensão de aspectos significativos dos fatos apresentados como notícias.

Conforme explica Sodré, a mídia atual (cibernética) não é prioritariamente informativa, mas conectiva. Voltada para a conexão dos sujeitos, ela é mais sintaxe (ordenação) do que semântica (significação), traduzindo-se, o jornalismo, em "jornalismo indicial", o qual, de acordo com o professor, funciona por contigüidade mecânica, por aproximação, por contato, e não pela significação propriamente dita - tal como explicitado por Pierce a respeito do índice que, ao lado do ícone (referente ao funcionamento da imagem) e do símbolo (referente ao domínio dos sistemas lingüísticos), corresponde a um dos três tipos de signos possíveis. Ainda segundo Sodré, toda imagem tende ao indicial, mas a palavra, ao se tornar indicial (sem significado), serve apenas para aproximar, tornando-se palavra vazia. Tal descrição

[...] aplica-se perfeitamente ao tipo de texto fugaz e fragmentário que caracteriza tanto a televisão quanto as modalidades enunciativas do digitalismo cibernético.

\section{$[\ldots]$}

Na tevê, no espaço virtual ou na nova realidade dos grandes espaços urbanos, a predominância dos fluxos contribui para dispersar o antigo tropismo integrador do sujeito, arrastando-o a uma espécie de errância cognitiva, em que são velozes e contingentes os procedimentos de leitura ou de atenção (SODRÉ, 2006, p.108). 
Ou seja, seguindo esta lógica, a visão pura e simples do fato remete ao índice, provocando a sensação de que se pode prescindir dos argumentos racionais. Quando o índice é prevalente, afirma Sodré, até mesmo as palavras perdem a força significativa em função do "indicar". Desta forma e, em ritmo cada vez mais acelerado, garante o professor, assiste-se a substituição da informação do acontecimento pelo acontecimento da informação.

A lógica contemporânea é a da temporalidade imediata, que corresponde a uma desvalorização da memória, frente a um presente contínuo e efêmero. $\mathrm{O}$ que, de acordo com Sodré, corrobora com a idéia de que a crise dos jornais não vem da internet, mas de uma mudança de tempo na vida das pessoas. O durável, o estável, é posto em crise, ficando afetada, então, a própria periodização da existência, num momento em que, segundo o professor, as etapas se diluem no frenesi da presença na rede e, por conseguinte, o acontecer ininterrupto sobrepõe-se ao acontecer marcado ritmicamente.

Entretanto, nunca é demais lembrar, conforme o faz Barbero, que a informação é matéria-prima da cidadania, ou seja, para participar da vida em sociedade, há que se saber o que está se passando. Mas como fazê-lo, se hoje os meios não acompanham os acontecimentos, não dão as pessoas condições de compreender o que se passa? Há cada vez menos narração e simplesmente a pontuação dos fatos. "Textos curtos e em carreira suicida", alerta Barbero, tentam competir com a TV e a web, em lugar de construírem os grandes gêneros que não se encontram em nenhuma delas.

Ou seja, segundo ele, a imprensa escrita deve encontrar e transformar seus próprios gêneros, fugindo da lógica do mais curto. O autor sugere ainda que os meios são uma grande fábrica de um 'presente autista', "que não nos conecta com nada: o que passa aqui e o que passa lá, no mundo e no país". Não se trata, esclarece, de um presente rico e denso, mas de um presente sem perspectiva histórica, sem memória. 
"A única maneira de enfrentar a violência é fazendo com que as pessoas pensem", complementa Barbero, lembrando, no entanto, que os meios perderam por completo o sentido da informação para que as pessoas pensem de uma forma ampla, contextualizada; para que elas debatam.

Não obstante, conforme esclarece Andreas Huyssen, "o boom da memória" pode ser interpretado como um sinal potencialmente saudável de contestação dessa grande fábrica de um 'presente autista':

uma contestação do hiperespaço informacional e uma expressão da necessidade humana básica de viver em estruturas de temporalidade de maior duração, por mais que elas possam ser organizadas. É também uma formação reativa de corpos mortais que querem manter sua temporalidade contra um mundo de mídia que esparge sementes de uma claustrofobia sem tempo e engendra fantasmas e simulações. Nesta visão distópica de um futuro high-tech, a amnésia não seria mais parte da dialética entre memória e esquecimento. Ela seria seu "outro" radical, decretando o verdadeiro esquecimento da própria memória: nada para lembrar, nada para esquecer (HUYSSEN, 1997, p.20).

Em "Memórias do modernismo", Huyssen defende que se deve pensar a memória e a amnésia juntas, ao invés de simplesmente opô-las. O autor argumenta que "as convulsões mnemônicas" da cultura atual parecem mais caóticas, fragmentárias e flutuantes, necessitando, pois, de uma 'âncora temporal'. Nesse sentido, a memória representa, segundo ele,

a tentativa de diminuir o ritmo do processamento de informações, de resistir à dissolução do tempo na sincronicidade do arquivo, de descobrir um modo de contemplação fora do universo da simulação, da informação rápida e das redes de TV a cabo, de firmar algum "espaço-âncora" num mundo de desnorteante e muitas vezes ameaçadora heterogeneidade, não sincronicidade e sobrecarga de informações (HUYSSEN, 1997, p.18).

Firmar algum "espaço-âncora". Talvez seja essa a tarefa dos jornais impressos no contexto da comunicação digital. Para tanto, é imperioso retomar o tempo lento, mesmo que na contramão de uma sociedade cuja máxima parece ser a da disponibilização de informações desenfreada e aceleradamente. A idéia é ter os jornais como pausa, reflexão, momento de selecionar e aprofundar os 
conhecimentos, diante das infinitas informações, atualizadas a todo o momento e oferecidas de forma contínua pelos modernos canais de comunicação.

Por esta razão, defende-se que o jornalismo impresso deve buscar a qualidade, procurando, sempre que possível, ser extensivo, explicativo, analítico e interpretativo. O que implica, dentre outras ações, estar apto a estabelecer relações, a contextualizar e a desenvolver os temas a partir de diferentes pontos de vista, e não de forma segmentada e fragmentária. 


\section{Referências}

BENJAMIN, Walter. Magia e técnica, arte e política: ensaios sobre literatura e história da cultura. Obras Escolhidas vol. I. São Paulo: Brasiliense, 1987.

CASTELLS, Manuel. A sociedade em rede. Volume I. São Paulo: Paz e Terra, 1999.

HUYSSEN, Andreas. Memórias do modernismo. Tradução de Patrícia Farias. Rio de Janeiro: UFRJ, 1997.

MARTÍN-BARBERO, Jesús. "Tecnicidades, identidades e alteridades: mudanças e opacidades da comunicação no novo século". In: MORAES, Dênis de (org). Sociedade midiatizada. Rio de Janeiro: Mauad, 2006. p. 51-79.

Dos meios às mediações: comunicação, cultura e hegemonia. Tradução:

Ronald Polito e Sérgio Alcides. 2. ed. Rio de Janeiro: Editora UFRJ, 2003.

MEYER, Philip. Os jornais podem desaparecer?: como salvar o jornalismo na era da informação. Tradução: Patricia De Cia. São Paulo: Contexto, 2007.

MORAES, Dênis de. "A tirania do fugaz: mercantilização cultural e saturação midiática". In: MORAES, Dênis de (Org.). Sociedade midiatizada. Rio de Janeiro: Mauad, 2006. p. 33-49.

SODRÉ, Muniz. As Estratégias Sensíveis: afeto, mídia e política. Petrópolis, RJ: Vozes, 2006.

Antropológica do Espelho: uma teoria da comunicação linear e em rede.

Petrópolis, RJ: Vozes, 2002.

A forma gloriosa da notícia. Disponível em: http://observatorio. ultimosegundo.ig.com.br/artigos.asp?cod=428IMQ002.

SOUZA SILVA, Rafael. O zapping jornalístico: da sedução visual ao mito da velocidade. Tese (Doutorado em Comunicação e Semiótica). São Paulo: PUC-SP, 1996.

WOLF, Mauro. Teorias das comunicações de massa. São Paulo: Martins Fontes, 2005. 

Comunicação Comunitária (LECC), da ECO/UFRJ.

2 "Zapar", termo que remete a atividade do zapper: corte, mudança, movimento, velocidade. Palavra originária do aparelho ad-zapper, inventado pelos norte-americanos, para mudança dos canais de rádio e televisão através do controle remoto (SOUZA SILVA, 1996: 12). 